\title{
EFFECT OF LOAD, TIME AND TEMPERATURE OF WATER ON WATER CONSUMPTION AND ELECTRICAL ENERGY CONSUMPTION OF WASHING MACHINE: AN EXPERIMENTAL STUDY
}

\author{
M. THIRUGNANAM ${ }^{1}$, S. SENTHILRAJA ${ }^{2}$, R. GANGADEVI ${ }^{3} \&$ R. MARIMUTHU ${ }^{4}$ \\ ${ }^{1,2,3}$ Assistant Professor, Department of Mechatronics Engineering, SRM Institute of Science and Technology, \\ Kattankulathur, India \\ ${ }^{4}$ Associate Professor, School of Electrical Engineering, Vellore Institute of Technology, Vellore, India
}

ABSTRACT
Due to the depletion of water level and increasing of energy demand, there is a need for energy efficient system increasing
in recent years. In this paper, the variation of water consumption and electrical energy consumption caused by load, the
temperature of water and time in a top loaded vertical axis portable washing machine and the outcomes this study are also
discussed. A $3 \mathrm{~kg}$ of DMR mini wash (model: DMR $30-1208)$ was used in this study. An experimental study was conducted
with three different loads (i.e. $1 \mathrm{~kg}, 2 \mathrm{~kg}$ and $3 \mathrm{~kg})$, three different operating times (i.e. $1 \mathrm{hr}, 2 \mathrm{hrs}$ and $3 \mathrm{hrs)}$ and three
different water temperatures $\left(30^{\circ} \mathrm{C}, 40^{\circ} \mathrm{C}\right.$ and $\left.50^{\circ} \mathrm{C}\right)$. The experimental results revealed that the consumption of water
increased with an increase of load and time also it decreased with an increase of water temperature also the electrical
energy consumption increased with an increase of load, time and water temperature.
KEYWORDS: Washing Machine, Water Consumption, Energy Consumption

Received: Jun 09, 2020; Accepted: Jun 29, 2020; Published: Aug 11, 2020; Paper Id.: IJMPERDJUN2020720

\section{INTRODUCTION}

Due to increasing electrical demands and climate changes, the Indian government is giving more attention to reduce the energy and water consumption of all home appliances. Among all other home appliances, washing machine is one of the most widely used and more energy and water consuming device in all houses. Washing machine is a mechatronics system which consists of pump, filter, motor, sensors and heater etc. Hence many industries and researchers were concentrated to improve the efficiency of washing machine by using different techniques.

JacetBuskiewicz and GrzegorzPittner [1] analyzed and reduced the vibration of front loaded drum type washing machine using new electromechanical dampers. The influence of different parameters on the stability of vertical and horizontal axis washing machines was studied by Chen et al [2, 3, 4]. The energy consumption and laundry program of front loading washing machine was optimized by Bao et al. [5.the results showed that the one third of energy consumption was reduced after the optimization under the same conditions. Yun and Park [6] studied the influence of fabric movement on washing efficiency in a horizontal axis drum type washing machine. This study results revealed that the energy and time was saved about $25 \%$ and $27 \%$ respectively by using optimal algorithm and also $4.8 \%$ washing efficiency was increased.

A simulation and experimental work was carried out by Campos and Hermes [7] to analyze the detergent movement in top loading washing machine. Bandita et al. [8] studied the use of recycled water in washing machine using SWOT analysis. Luca et al. [9] analyzed the influence of mechanical, electrical and control components on 
the characteristics of control performance of washing machine. The experimental and simulation study was carried out to investigate the performance of washing machine with hot water in closed circulation loop by person [10]. The noise and vibration of two different types of washing machine were optimized using neural network model by Manderes [11].

In the previous studies the authors were analyzed the effects of different parameters such as vibration, noise etc. on the performance of commercially available washing machine. Only few researchers studied the water and energy consumption of washing machine under different operating conditions. This study presents the effects of load and temperature of water on the water and electrical consumption of top loaded vertical axis portable washing machine.

\section{WASHING MACHINE DESCRIPTION}

The top loaded vertical axis portable washing machine consists of cabinet, tub, basket, agitator, motor and dampers. Generally, the water stored in the tub for washing the cloths. The high torque single phase induction motor is acting as the prime mover and used to rotate the drum. To reduce the transmission losses, the drum is directly connected to the motor without using any transmission elements such as gears, belts etc. The rotation of motor and drum causes the vibration and the vibration is transmitted to the dampers through the cabinet. The digital flow sensor and energy meter is used to measure the water and electrical energy consumption in this study. The specification and Schematic diagram of the experimental setup used in this study is given in Table 1 and Figure 1 respectively.

Table 1: Specification of Washing Machine

\begin{tabular}{|l|l|}
\hline \multicolumn{1}{|c|}{ Parameters } & \multicolumn{1}{c|}{ Description } \\
\hline Make & DMR Mini Wash \\
\hline Model & DMR 30 - 1208 \\
\hline Capacity & $3 \mathrm{~kg}$ \\
\hline Overall size & $40 \times 40 \times 50$ in cm (LxBxH) \\
\hline Motor & Single phase induction motor \\
\hline Spin power & 240w \\
\hline Washing Style & Clockwise and anticlockwise \\
\hline
\end{tabular}

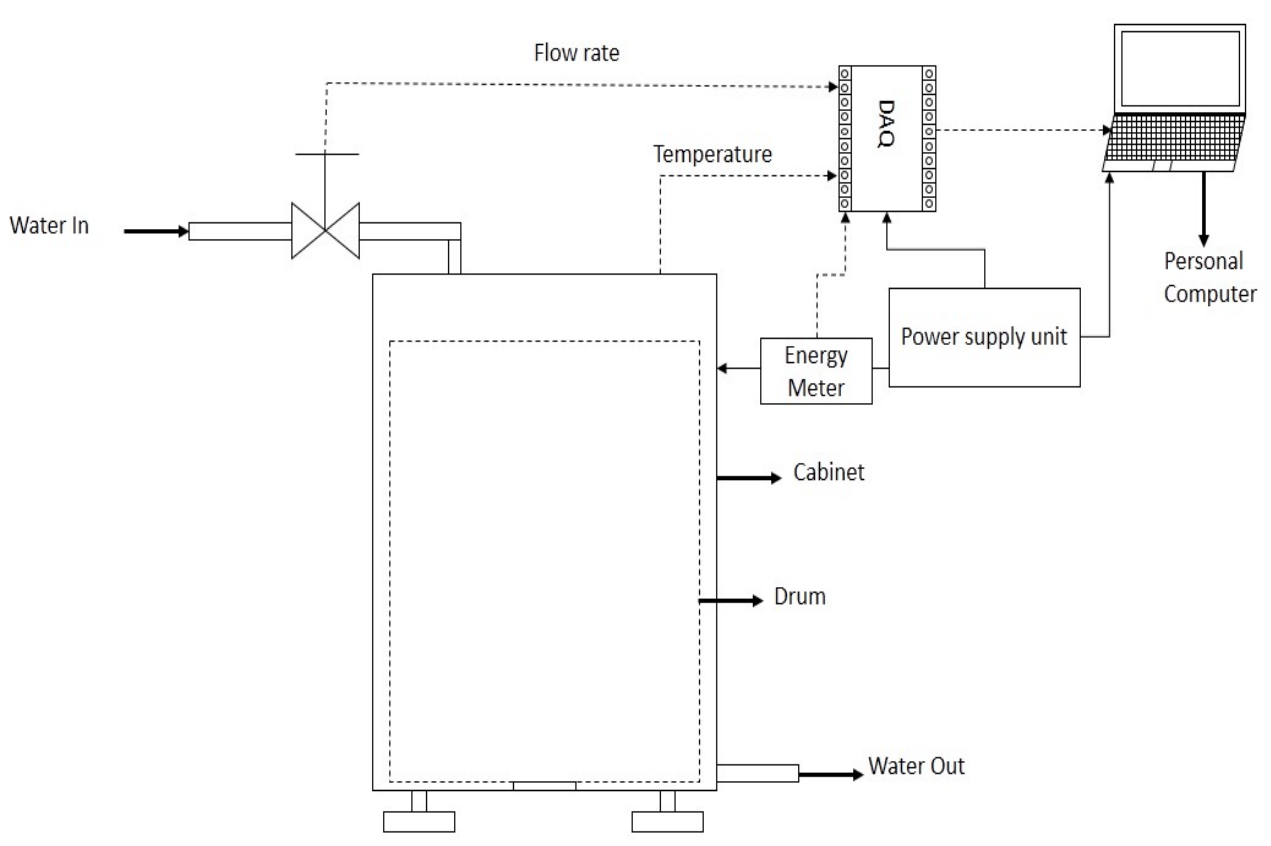

Figure 1: Schematic Diagram of Experimental Set Up. 


\section{RESULT AND DISCUSSIONS}

In this work, the test was conducted for different load conditions and different temperature of water. The effects of load and water temperature on water and electrical energy consumption was reported in this section

\section{Effects of Load and Temperature on Water Consumption}

Many factors such as energy consumption, water consumption, cost etc. are need to consider while selecting washing machine. The variations of water consumption with load and different time at $30^{\circ} \mathrm{C}, 40^{\circ} \mathrm{C}, 50^{\circ} \mathrm{C}$ water temperature are illustrated in Figure 2, Figure 3 and Figure 4 respectively. The results clearly shows that the consumption of water increases with increase of load for all temperatures also it is observed that the water consumption decreases with increase of temperature of water.

At $30^{\circ} \mathrm{C}$ for $1 \mathrm{~kg}$ load condition, the washing machine consumed 17 lts and 24 lts per wash at 30 and $50 \mathrm{~min}$ operating time respectively. In the case of $2 \mathrm{~kg}$ and $3 \mathrm{~kg}$ load condition, the water consumption increased to $18,25 \mathrm{lts}$ and 20, 26 lts respectively for the same operating time. At $50^{\circ} \mathrm{C}$, the consumption of water varies from 15 lts, 16 lts and 18 lts at 30 min operating condition to 20 lts, 21 lts and 22 lts at 50 min operating condition respectively.

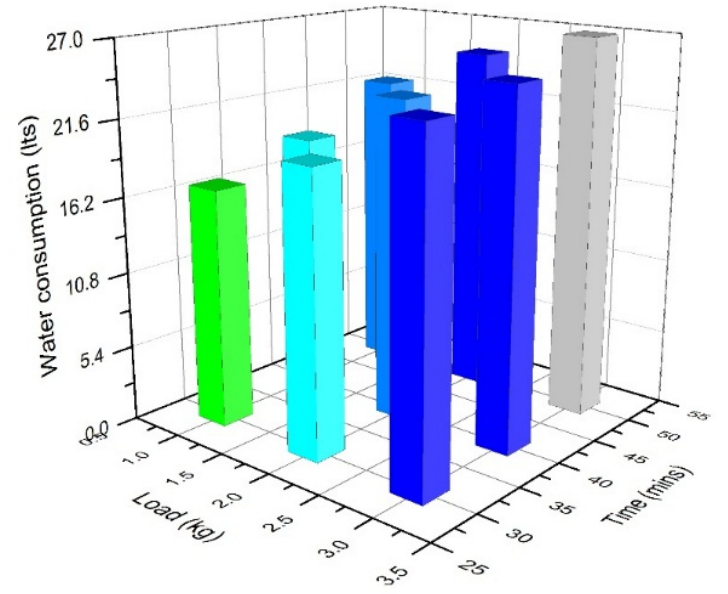

Figure 2: Variations of Water Consumption with Different Load at $30^{\circ} \mathrm{C}$ Water Temperature.



Figure 3: Variations of Water Consumption with Different Load at $40^{\circ} \mathrm{C}$ Water Temperature. 


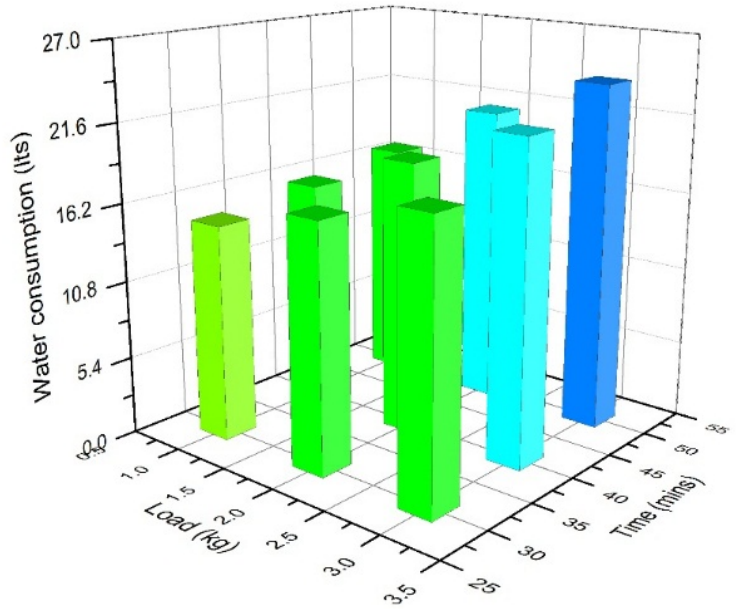

Figure 4: Variations of Water Consumption with Different Load at $50^{\circ} \mathrm{C}$ Water Temperature.

It can be inferred from the experimental results, that the consumption of water decrease with increase of water temperature also it increases with increase of time and load. At high load conditions, more cloths are loaded into the drum. Hence, more water needed to wash and rinse the cloths. At high temperature, the detergents reacts with water very quickly. Thus the oily and greasy solids can be cleaned very quickly. Thus only less quantity of water required to wash the cloths. Because of this reason, the consumption of water decreases with increase of water temperature.

\section{Effects of Load and Temperature on Electrical Energy Consumption}

Motor is one of the most electrical energy consuming device in washing machine. Based on the operation, motor is running with different speed and different time. The energy consumption for washing is always higher than the rinsing and spinning process. The variation of electrical energy consumption for $1 \mathrm{~kg}$ load condition at $30^{\circ} \mathrm{C}$ water temperature is given in Figure 5. The outcome of this graph clearly shows that the electrical energy consumption increases with increasing load, water temperature and time. The maximum of $48.3 \mathrm{Wh}$ electrical energy is consumed for the machine with $3 \mathrm{~kg}$ load and 50 min of operating condition. The minimum of $33.5 \mathrm{wh}$ is observed for $1 \mathrm{~kg}$ load and $30 \mathrm{~min}$ operating conditions.

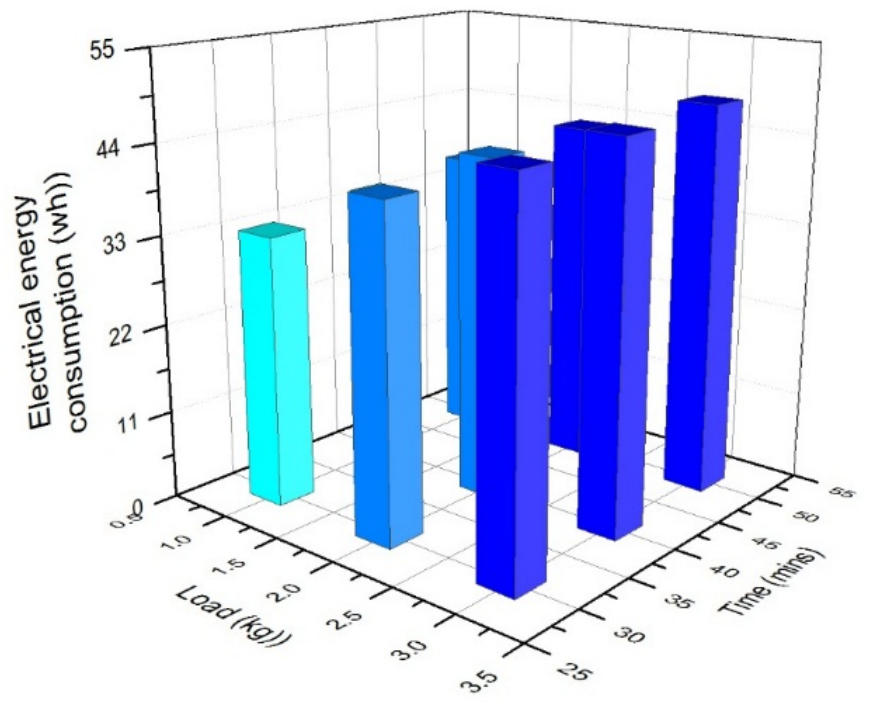

Figure 5: Variations of Electrical Energy Consumption with Different Load at $30^{\circ} \mathrm{C}$ Water Temperature. 
Figure 6 depicts the effects of load and time on electrical energy consumption at $40^{\circ} \mathrm{C}$ water temperature. It is found that the electrical energy consumption is $35.1 \mathrm{wh}$ at $1 \mathrm{~kg}$ load and $30 \mathrm{~min}$ operating condition and $44.7 \mathrm{Wh}$ and $50.6 \mathrm{Wh}$ at $2 \mathrm{~kg}$ and $3 \mathrm{~kg}$ load condition and $40 \mathrm{~min}$ and 50 min operating conditions respectively.

Figure 7 shows the variation of electrical energy consumption for different load and different operating time at $50^{\circ} \mathrm{C}$ water temperature. It can be inferred that the consumption of electrical energy varies from $36.7 \mathrm{Wh}$ at low load condition and $30 \mathrm{~min}$ operating condition to $38.7 \mathrm{wh}$ at high load and $50 \mathrm{~min}$ operating condition. For $2 \mathrm{~kg}$ and $3 \mathrm{~kg}$ load it varies from $43.2 \mathrm{Wh}$ and $49.8 \mathrm{Wh}$ at $30 \mathrm{~min}$ operating condition to $45.9 \mathrm{Wh}$ and $52.1 \mathrm{Wh}$ at $50 \mathrm{~min}$ operating condition respectively. At high temperature, the heater consumed more electrical energy to heat the water. Thus the consumption of electrical energy increases with increase of temperature of water.

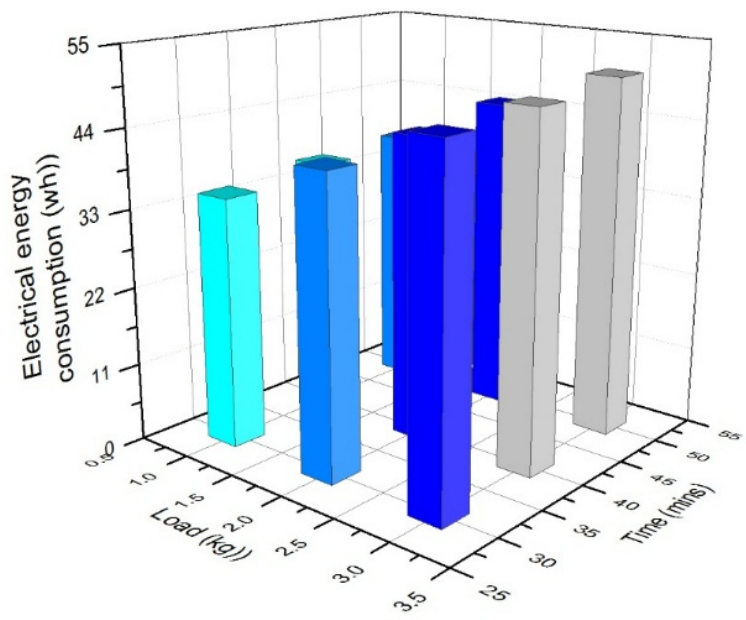

Figure 6: Variations of Electrical Energy Consumption with Different Load at $40^{\circ} \mathrm{C}$ Water Temperature.

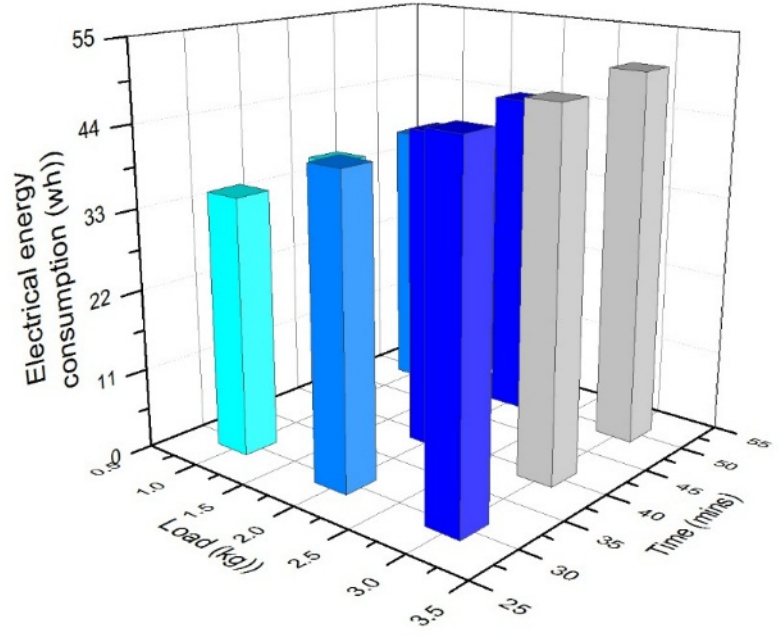

Figure 7: Variations of Electrical Energy Consumption with Different Load at $50^{\circ} \mathrm{C}$ Water Temperature.

\section{CONCLUSIONS}

In this study, an experimental set up was fabricated to investigate the effects of load and water temperature on water consumption and electrical energy consumption of portable vertical axis top loaded washing machine. The important results of this study are as follows. 
- The consumption of water increased with increase of load and time also it decreased with increase of water temperature.

- The maximum water consumed for $3 \mathrm{~kg}$ load at $50^{\circ} \mathrm{C}$ water temperature and $50 \mathrm{~min}$ operating time. The minimum water consumption was obtained for $1 \mathrm{~kg}$ load at $30^{\circ} \mathrm{C}$ water temperature and 30 min operating time.

- The electrical energy consumption increased with increase of load, time and water temperature.

- The maximum electrical energy consumption was obtained for $3 \mathrm{~kg}$ load at $50^{\circ} \mathrm{C}$ water temperature and $50 \mathrm{~min}$ operating time. The minimum electrical energy consumed for $1 \mathrm{~kg}$ load at $30^{\circ} \mathrm{C}$ water temperature and $30 \mathrm{~min}$ operating time.

\section{REFERENCES}

1. Jacek Buskiewicz, GrzegorzPittner. 2016. Reduction in vibration of a washing machine by means of a disengaging damper, Mechatronics 33: 121-135.

2. Hai-Wei Chen, Qiu-Ju Zhang, Xiao-Qing Wu. 2015. Stability and dynamic analyses of a horizontal axis washing machine with a ball balancer, Mechanism and Machine Theory 87: 131-149.

3. Hai-Wei Chen, Qiu-Ju Zhang. 2011. Stability analyses of a vertical axis automatic washing machine with a hydraulic balancer, Mechanism and Machine Theory 46(7): 910-926.

4. Abrol, Sanchita, and Deepak Chhabra. "Experimental investigations of piezoelectric energy harvesting with turbulent flow." International Journal of Mechanical and Production Engineering Research \& Development 8.1 (2018): 703-710.

5. Wei Bao, Hugh Gong, Xuemei Ding, Yue Xue, Pengfei Li, Weichao Fan. 2017. Optimizing a laundering program for textiles in a front-loading washing machine and saving energy, Journal of Cleaner Production, 148: 415-421.

6. Hai-Wei Chen, Qiu-Ju Zhang. 2010. Stability analyses of a vertical axis automatic washing machine without balancer, Journal of Sound and Vibration, 329, 11: 2177-2192.

7. Kidiyoor, Abhilash, and Kripa M. Suvarna. "A Study on Performance of Solar Water Heater Using Lauric Acid-Water as Thermal Storage System."TJPRC: International Journal of Heat and Mass Transfer (TJPRC: IJHMT) Vol. 1, Issue 1, Jun 2016, 9-14

8. Chang sang Yun, Chung Hee Park. 2015. The effect of fabric movement on washing performance in a front-loading washer III: Focus on the optimized movement algorithm, Textile Research Journal, 86, 6: 563-572.

9. Luiz G.C.Campos, Christian J.L.Hermes. 2016. Experimental evaluation and transient simulation of detergent transport in household vertical axis washing machines, Chemical Engineering Research and Design, 109: 720-729.

10. Patil, Bhagyashree, and MarutiLimkar. "Machine to Machine Communication Based Electricity Monitoring and Billing System." International Journal of Electrical and Electronics Engineering Research (IJEEER) ISSN (P) (2016).

11. BanditaMainali, HuиHao Ngo, WenshanGuo, Thi Thu Nga Pham, Archie Johnston. 2011. Feasibility assessment of recycled water use for washing machines in Australia through SWOT analysis, Resources, Conservation and Recycling, 56, 11: 87-91.

12. Yousif, R. "Measuring the effectiveness of demarketing in influencing consumer behavior of individuals." International Journal of Business Management \& Research 4.5 (2014): 31.

13. Luca Bascetta, Paolo Rocco, Andrea Maria Zanchettin, GianantonioMagnani. 2012. Velocity control of a washing machine: A mechatronic approach, Mechatronics, 22: 778-787. 
14. Tomas Persson. 2007. Dish washer and washing machine heated by a hot water circulation loop, Applied Thermal Engineering, 27, 1: 120-128.

15. Menderes Kalkat. 2014. Experimentally vibration and noise analysis of two types of washing machines with a proposed neural network predictor, Measurement, 47: 184-192.

\section{AUTHORS PROFILE}

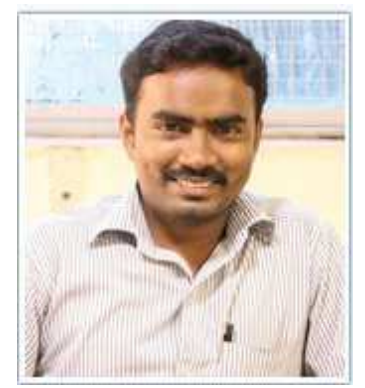

M.Thirugnanam received his B.E. degree in Mechanical Engineering from Madras University, Chennai. He has obtained his Master's degree in Engineering design from Anna University, Coimbatore in 2011. He is now working on a doctoral degree in SRMIST. His research interests include molecular dynamics, design of machine elements. He has published 2 International Journals and 2 international conferences.

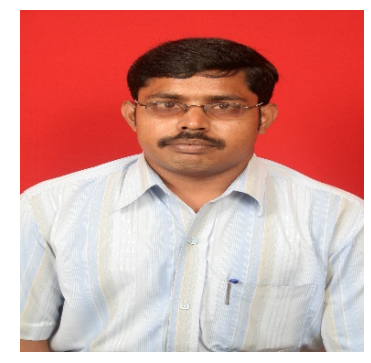

S.Senthilraja received his B.E. degree in Mechanical Engineering from Bhrathiyar University, Coimbatore, in 2001. He has obtained his Master's degree in Mechatronics Engineering from Anna University, Chennai in 2006. He is now working on a doctoral degree in Anna University. His research interests include Heat transfer Nanofluids, Internal Combustion Engine, and Engine Cooling System. He has published 12 International Journals and 2 international conferences.

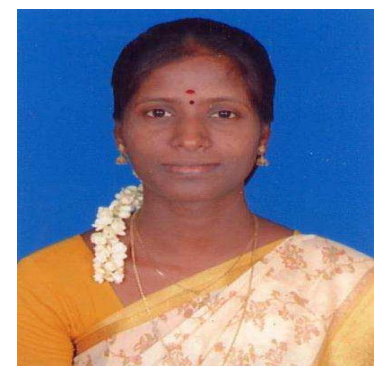

R. Gangadevi was awarded a bachelor's degree in Electrical and Electronics engineering from Madras University in Chennai, Tamilnadu, India in 2004, she graduated with a Master of Engineering degree in mechatronics engineering from Anna University, Chennai in May 2007. She is pursuing Ph.D. in mechanical engineering at SRM University, Chennai. She is working as an Assistant professor at SRM University. She has published 13 International Journals and 2 international conferences. 


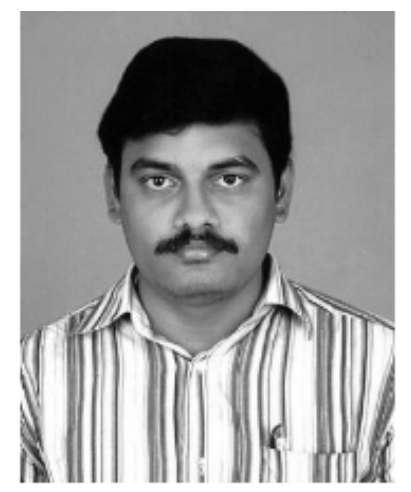

R. Marimuthu received the bachelor's degree in electronics and instrumentation from Bharathiyar University, India, and the master's degree from Anna University, India. He is currently an Assistant professor (Sr.,) with the School of Electrical Engineering, VIT University, India. He has authored 20 scopus indexed papers in different journals and conferences. His current research area is low power VLSI, high speed architecture, and embedded systems 